\title{
EDITORIAL
}

\section{CBAB: a decade of success!}

The Board of Directors of the Brazilian Association of Plant Breeding - SBMP (www.sbmp.org.br) - and the Editorial Board of the journal Crop Breeding and Applied Biotechnology-CBAB (www.sbmp.org.br/cbab/siscbab/index.php) have the honor to present the first special edition of CBAB. This 10-year anniversary edition is a milestone in the history of the journal, worth celebrating, representing the result of the collective efforts of the SBMP, CBAB, authors, reviewers and particularly the translator. It is worth mentioning that a decade of existence of a contextualized journal in an emerging country such as Brazil is a momentous fact, demonstrating the dynamic development of plant improvement underlying the global success of the Brazilian agribusiness. But before highlighting specific subjects of the anniversary issue, it is worth recollecting some historical details that have shaped the SBMP and CBAB.

The SBMP, firstly, was created in 1999, during a meeting at the Federal University of Viçosa, congregating the desire of the 99 plant breeders present at that event. The SBMP is a nonprofit scientific organization that brings together scholars in plant breeding from different Brazilian institutions. The objectives of the SBMP are to stimulate the development of plant breeding in the country; to enable and coordinate exchange among scientists dedicated to research, teaching and plant-breeding-related activities; to represent and advise governmental agencies and other institutions in matters related to plant breeding; to establish and promote sponsored inducement prizes awarded at congresses, to stimulate scientific activities at the undergraduate and graduate level, and also to decorate breeders for relevant work in teaching, research and extension in the area; to guide activities related to the professional practice in the field of plant breeding; to promote, initiate and/or sponsor courses of specialization and extension for the education and training of breeders; to publish issues of Crop Breeding and Applied Biotechnology, the official organ of the institution, and other proceedings; to foster the dissemination of topic -related knowledge by the publication of books, monographs, newsletters, films etc; and encourage the improvement of subject-related education at all levels.

Over the course of the first 12 years, the SBMP was directed by six administrative boards, which all tried to meet the objectives and strengthen the Association. Today, the membership of the Association has risen to 421. The growth of the SBMP is reflected in the regular participation of current and future plant breeders in the national congress held every two years. For this latest edition of the congress - the 6th CBMP - the limited number of 1000 participants was not enough to meet the demand. This shows the sound establishment of the scientific association, which has implemented the majority of its statutory objectives.

With regard to the $\mathrm{CBAB}$, the magazine has published around 616 articles in the last 10 years. This scientific collection has promoted the $\mathrm{CBAB}$ as the leading journal of plant breeding in Latin America. It all began in 2001, when the SBMP founded CBAB and Professor Dr. Deonísio Destro was appointed as the first Editor-in-chief. Times were hard then, and if it were not for the perseverance of Professor Destro, the journal would never have become what it is today.

As of 2004, Professor Dr. L.A.S. Dias was entrusted with the position of editor-in-chief. In the same year, the editorial board implemented an on-line article management system (SGA), resulting in greater efficiency, speed and security in the publication of the papers. Also in 2004, the journal's website was restructured and became more functional and clearly laid out. Once the entire collection of information of a reputable journal was available on the CBAB website, the invitation came in 2006 to be listed in one of the world's most renowned databases, Scopus (www.scopus.com), which currently indexes around 17 thousand journals. In 2008, after four years of evaluation, Thomson Reuters (http:// thomsonreuters.com/), formerly ISI, approved the inclusion of CBAB in its database, the most prestigious worldwide. Due to this admission, a first impact factor of CBAB (0.487) was calculated in 2009 and published in 2010 in Journal Citation Reports - JCR. Also in 2010, the journal was listed in SciELO - Scientific Electronic Library Online (www.scielo.br/ cbab) - the largest database of Latin America. Recently, in 2011, the latest JCR journal impact factor advanced the CBAB to 0.509 . The outlook is very positive and it is possible to increase the impact factor towards 1 in the coming years.

In this special CBAB issue, the reader is presented with highly relevant contemporary articles written by experts in their fields, covering subjects included in the program of the 6th Brazilian Congress of Plant Breeding in 2011, in Buzios, RJ. Some of the issues addressed are, e.g., the use of mixed model techniques to increase selection accuracy in autogamous and allogamous species; the state-of-art of improvement of alcohol and oilseed species for biofuel production; the improvement of a model plant such as corn projected for a future environment marked by climate changes; the successful 
Brazilian forest improvement program; and marker-assisted selection. This is the first special edition of $\mathrm{CBAB}$ and certainly only the first of many others to come.

The Editorial Board of CBAB and the Board of Directors of the SBMP hope you enjoy your reading!

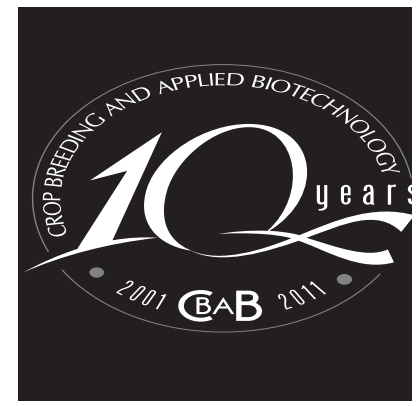

LAS Dias Messias Gonzaga Pereira

Editor-in-chief of CBAB President of SBMP 